\title{
Crítica situada: cuatro postulados sobre el trabajo de la crítica literaria en la cotidianeidad
}

\author{
Situated criticism: four postulates \\ on the work of literary criticism on cotidianity \\ Crítica situada: quatro postulados \\ sobre o trabalho da crítica literária na cotidianidade
}

Lucía Tennina*

\section{Resumen}

Este artículo consiste en una serie de lineamientos dirigidos a repensar nuestro lugar de habla en tanto críticos literarios en función de establecer un diálogo atractivo y efectivo con la cotidianeidad. Se parte de una idea de crítica literaria "situada" pensada más que como una disciplina, como una práctica que permite activar sensibilidades sobre lo establecido, por lo que crea otras formas de imaginarlo. La hipótesis principal afirma que los estudiosos de la literatura deben pensarse a partir de cuatro identidades: la de escritores, la de archivistas, la de etnógrafos y la de difusores. A partir de ahí, se analizan las producciones de Josefina Ludmer, Regina Dalcastagnè, Sylvia Molloy y Víctor Vich prestando atención a sus operaciones alrededor del canon hegemónico y sus metodologías específicas de trabajo.

Palabras-clave: Crítica literaria, lugar de habla, literatura contemporánea.

\begin{abstract}
This article consists of a series of guidelines aimed at rethinking our place of speech as literary critics in order to establish an attractive and effective dialogue with cotidianity. It is structured from an idea of "situated" literary criticism thought more than as a discipline, as a practice that allows activating sensitivities about what is established by creating other ways of imagining it. The main hypothesis states that professionals of literature must be thinked from four identities: that of writers, that of archivists, that of ethnographers and that of diffusers. From there, the productions of Josefina Ludmer, Regina Dalcastagnè, Sylvia Molloy and Víctor Vich are analyzed, paying attention to their operations around the hegemonic canon and their specific work methodologies.
\end{abstract}

Keywords: Literary criticism, place of speech, contemporary literature.

\section{Resumo}

Este artigo consiste em uma série de alinhamentos que visam repensar nosso lugar de fala como críticos literários, a fim de estabelecer um diálogo atraente e efetivo com a cotidianidade. Parte-se de uma ideia de crítica literária "situada" pensada mais do que como disciplina, como prática que permite ativar sensibilidades sobre o estabelecido, criando outras formas de imaginá-lo. A hipótese principal afirma que os estudiosos de literatura devem ser pensados a partir de quatro identidades: a dos escritores, a dos arquivistas, a dos etnógrafos e a dos difusores. A partir daí, são analisadas as produções de Josefina Ludmer, Regina Dalcastagnè, Sylvia Molloy e Víctor Vich, prestando atenção nas suas operações em torno do cânone hegemônico e suas metodologias de trabalho específicas.

Palavras-chave: crítica literária, lugar de fala, literatura contemporânea.

En una de las páginas del libro El demonio de la teoría, de Antonie Compagnon (2015), se lee:

Hacia 1970 la teoría literaria se encontraba en pleno auge y ejercía un inmenso atractivo en los jóvenes de mi generación. Con diversas denominaciones - nueva crítica, poética, estructuralismo, semiología, narratología - brillaba con luz propia. Cualquiera que haya vivido aquellos mágicos años lo recordará con nostalgia (p. 11).

\footnotetext{
*Universidad de Buenos Aires, Buenos Aires, Argentina. (Dhttps://orcid.org/0000-0002-5652-6234. E-mail: luciatennina@gmail.com
} 
Hoy estamos lejos de pensar que la teoría literaria ejerce una atracción para la juventud en estos tiempos. Esa luz, de acuerdo con Antonie Compagnon, se debilitó poco a poco una vez que la teoría se institucionalizó, se transformó en método y se escolarizó "reducida a unas cuantas recetas, trucos y artimañas" (2015, p. 12). La crítica literaria edulcorada parece ser la que hasta hoy en día está en actividad. No es ninguna novedad que nuestra época registra un notable cambio en relación con el rol del crítico literario, visible en el no compromiso político, a diferencia de los años 60/70, así como en la especialización del saber. Maristella Svampa, en su artículo "Notas provisorias sobre la sociología, el saber académico y el compromiso intelectual" (2008, p 9-10), señala: "la excesiva profesionalización de las ciencias sociales que se registra a partir de los años 80 , constituyó una respuesta a la sobre-ideologización imperante en el campo académico en los años 60 y 70". Lo mismo se podría decir respecto de la crítica literaria y los estudios literarios. La consolidación del modelo de crítico literario profesional académico se tradujo en la adopción de una posición abstencionista en materia de compromiso intelectual y, en este sentido, la actividad se volvió profundamente autoreferencial y repetitiva, sin capacidad de tender puentes con otras realidades o lenguajes. Me refiero, cabe aclarar, no al trabajo intelectual, sino al trabajo académico, trabajos que coinciden en parte, pero no son lo mismo.

Hoy en día, en términos generales, los estudios de la literatura son una disciplina institucionalizada con un corpus de enseñanza de límites definidos y con un control estricto respecto de los objetos, los saberes y los métodos. En otras palabras, en términos generales, actualmente los estudiosos de la literatura nos formamos como administradores de los paradigmas establecidos, policías epistemológicos que operan en nombre de la estética y técnicos de un repertorio de preguntas de moda que hacen eco en los programas de estudios, congresos o libros publicados. Si la formación de los estudiosos de la literatura se reduce a eso, los críticos literarios nos iremos convirtiendo en representantes de una actividad que funciona desde la inercia y a la cual no le importa producir grandes cambios, sino gerenciar desde las reglas preestablecidas.

¿Cómo pensar, entonces, en los estudios literarios como siendo "atractivos" para estos tiempos?

Evoco, antes de continuar con las reflexiones, la referencia a un artículo que fue la inspiración para estas líneas. Se trata de un texto del crítico literario y cultural Víctor Vich, quien en 2018 publicó "¿Qué es un gestor cultural? En defensa y en contra de la cultura", un llamado de atención y un programa de acción dirigido al área de la gestión cultural que parte de la propuesta de que los gestores culturales deben formarse a partir de cuatro identidades (la de etnógrafo, la de curador, la de militante y la de administrador) en función de "intervenir en las prácticas injustas institucionalizadas en la sociedad, en los poderes que se ejercen en la vida cotidiana" (2018, p. 50). La lectura de ese texto resonó con fuerza en mis investigaciones alrededor de la producción crítica contemporánea que hace unos años vengo llevando a cabo y me inspiró a postular de manera contundente en este artículo una serie de lineamientos dirigidos a redefinir nuestro lugar de habla en función de establecer un diálogo atractivo y efectivo con, justamente, la vida cotidiana. De acuerdo con Vich en su artículo, "lo cotidiano es simultáneamente el lugar de la creatividad, de la agencia, el lugar donde se pueden ir produciendo pequeños cambios sociales" (2018, p. 48). Lo cotidiano, en este sentido, no remite solamente a la rutina y al hábito, sino que refiere también a la una idea de resistencia y transformación.

Una de las primeras afirmaciones del artículo de Vich dice: "Partamos sosteniendo que la cultura no es solo una buena palabra" (2018, p. 48). Extrapolando esta afirmación al terreno específicamente literario sigue siendo posible sostener que la literatura tampoco es siempre una "buena" palabra. No es posible partir de la base de que la literatura es algo siempre "positivo" para la sociedad, posicionada desde un lugar aurático e inocente. La literatura carga con silenciamientos, exclusiones y violencias que nosotros, como profesionales del área, no podemos relativizar ni debemos nunca olvidar. Visto desde lejos, con un ojo afinado, quizás se nota más. El conjunto de traducciones que circulan y los nombres de lxs autorxs brasileñxs que se conocen en mi país, Argentina, por ejemplo, parecerían dejar en claro que en un Brasil donde más de la mitad de la población es negra, no habría ni un solo escritor o escritora negros. Y, por más que existan traducciones de Machado de Assis o Lima Barreto, la imaginación que se tiene sobre el 
perfil de esos escritores es blancocéntrica. Y, por supuesto, fundamentalmente masculina. Esta caracterización se instala en las bibliotecas, se proyecta al sentido común y abona los hábitos discriminatorios y las prácticas excluyentes. Todavía hoy se sigue construyendo, desde las casas editoriales y académicas, una idea de literatura donde el racismo sigue siendo naturalizado, donde la diversidad se percibe como subalternidad, donde la desigualdad no se cuestiona y donde el valor se limita a unos pocos, escondido por detrás de un halo de objetividad e inocencia.

¿Qué posición tomar ante esta evidencia alarmante?

Propongo, haciendo eco del texto de Vich, que los estudiosos de la literatura debemos pensarnos a partir de cuatro identidades: la de escritores, la de archivistas, la de etnógrafos y la de difusores.

En primer lugar, es importante no perder de vista que lo que hacemos los profesionales de la literatura es escribir. Quizás esta afirmación no parezca una revelación muy notable, pero creo que no deja de ser importante llamar la atención sobre el hecho de que la actividad del día a día que nos define como profesionales es la escritura, más allá de la selección de un corpus y el análisis textual. Resulta necesario, entonces, como dice Nelly Richard en su artículo "La cita académica y sus otros", "correrse de la regla objetivadora del saber académico cuya pretensión de validez y sistematicidad se apoya generalmente en la indefinición de la persona" $(2009$, p. 73$)$ para asumir la verbalización de una primera persona que dé cuenta del lugar de habla en función de diversificar las perspectivas sociales. Como ya decía Barthes:

¿Acaso puede haber leyes de creación válidas para el escritor, pero no para el crítico? Toda crítica debe incluir en su discurso (aunque sea del modo más velado y más púdico) un discurso implícito sobre sí misma; toda crítica es crítica de la obra y crítica de sí misma (2003, p. 348).

Pensarnos como escritores nos lleva a descolonizar el conocimiento a partir del cuestionamiento respecto de la verdad objetiva científica que pesa sobre nuestro lenguaje. Resulta necesario posicionarse cada vez más a partir de la afirmación de una primera persona para ampliar no solamente la gama de producciones críticas, sino también el corpus de textos considerados como literarios. El posicionamiento del lugar de habla y del sujeto enunciador determinan las cuestiones a ser analizadas, es decir, los temas, y las perspectivas de abordaje.

Conviene, en este sentido, considerar las experiencias críticas de ciertos estudiosos de la literatura que se arrojaron a la experimentación, habiendo transitado anteriormente un modo de hacer crítica tradicional y conservador, permitiéndose ampliar el abanico de posibilidades respecto de lo que se considera como literario. Pienso, por ejemplo, en el libro "Aquí América Latina", de Josefina Ludmer (2010), texto híbrido, mezcla de diario, ficción, autobiografía, ensayo. Escrito los meses previos a la llamada "crisis" del 2001 en Argentina, trauma inolvidable de nuestra sociedad como consecuencia de las políticas neoliberales que destruyeron nuestra soberanía, el libro de Ludmer muestra la transformación del funcionamiento de la literatura y de la crítica literaria en una realidad confusa e irrepresentable. Este libro, escrito por una figura central en la crítica argentina, es un estudio sobre literatura pero que no la toma como objeto central, porque parte de la hipótesis de que la literatura contemporánea pone en cuestión los límites o fronteras del campo a partir de una serie de prácticas de escritura que experimentan con otros lenguajes y que ponen en jaque, básicamente, la idea de autonomía. Este acercamiento a lo social no se basa en una metodología sociológica, sino que comienza con la siguiente advertencia metodológica: "para poder entender el nuevo mundo (y escribirlo como testimonio, documental, memoria y ficción) necesitamos un aparato diferente del que usábamos antes" (Ludmer, 2010, p. 9). El nombre que le da a esta operación es el del subtítulo del libro, la "especulación", que tiene que ver con pensar y teorizar muchas veces sin base teórica y también con maquinar y calcular ganancias. Lo que lleva adelante es una especulación sobre ese presente del aquí y ahora tomando como base lo que ella llama "imaginación pública" esto es, "todo lo que circula, el aire que se respira, la telaraña, el destino" (Ludmer, 2010, p. 11). Habla, entonces, de lo que dicen los periódicos, las novelas de la televisión, las obras de teatro que va a ver. ¿Y cómo entra la literatura en ese entramado? 
Usar la literatura como lente, máquina, pantalla, mazo de tarot, vehículo y estaciones para poder ver algo de la fábrica de la realidad, implica leer sin autores ni obras: la especulación es expropiadora. No lee literariamente (con categorías literarias como obra, autor, texto, estilo, escritura y sentido) sino a través de la literatura, en realidadficción y ambivalencia. Usar la literatura para entrar en la fábrica de realidad (Ludmer, 2010, p. 12).

La literatura entra como un dato más que se le cruza a Ludmer y lo hace entrar por medio de diálogos con escritores o crítico: "Caminata con Tamara Kamenszain en el Jardín Botánico. Tema: cierta poesía actual" (...) "Qué contás? me dice Tamara cuando nos encontramos aquí para caminar y charlar sin parar...para caminarhablarcontar ¡Felicidad! ¿Cómo va tu diario del 2000?” (Ludmer, 2010, p. 105). Diálogos que, por otro lado, la corren a Ludmer del lugar auto-confirmante de la posición de autoridad en la temática: “Tamara cuenta: Más de una vez me dijiste que la poesía es algo que te deja medio perpleja, que no sabés qué decir cuando leés un poema" (Ludmer, 2010, p. 106). La literatura va entrando como parte del proceso de pensamiento de Ludmer que es un poco ese "caminarhablarcontar". Va mostrando la trastienda en primera persona del pensamiento, el proceso por ejemplo del descubrir a la literatura más allá de la idea de campo.

El libro de Josefina Ludmer es un experimento coral que muestra la transformación del funcionamiento de la literatura y de la crítica literaria a partir de, dice la autora, "una realidad que no quiere ser representada porque ya es pura representación" (Ludmer, 2010, p. 151). El texto de Ludmer en sí mismo es una "críticaficción" que no sigue las estructuras de un libro académico $\mathrm{y}$, en este sentido, abre también un debate en torno de los modos enunciativos de puesta en forma del conocimiento de la crítica.

Según Laura Alcoff, la filósofa panameña decolonial, el ejercicio de producción de pensamiento ligado a la asunción de la primera persona es una forma de descolonizar el pensamiento:

O projeto de decolonização epistemológica presume a importância epistêmica da identidade porque entende que experiências em diferentes localizações são distintas e que a localização importa para o conhecimento. Nossos argumentos poderão receber críticas de que mais uma vez estamos voltando à política identitária, que somos metafisicamente não sofisticados e politicamente retrógrados, uma crítica que também tem sido brandida da metrópole para as periferias da academia global. A crítica da política identitária tem mantido muitos "escravos" da acusação de um essencialismo político grosseiro e de falta de sofisticação teórica. Acredito que a inclinação anti-identidade tão prevalente na teoria social hoje é outro obstáculo para o projeto de decolonização do conhecimento, uma vez que isso debilita nossa habilidade de articular o que está errado com a hegemonia teórica do Norte global (2016, p. 136).

Como queda claro a partir de la afirmación de Alcoff, la asunción de una primera persona por parte de la producción crítica es una forma de desplazar el mito de neutralidad que acarrea una exclusión de las producciones académicas de los intelectuales negros, indígenas, travestis o, en términos generales, no blancos cuya prosa está atravesada por la inclusión de la vivencia como parte del ejercicio intelectual.

Sumada a esta identidad de escritor, propongo que los estudiosos de la literatura asumamos también el trabajo de archivista. Muchas veces sucede que, por más ampliación de las fronteras de habla que el crítico asuma, el corpus de análisis resulta reducido y siempre el mismo. Para contrarrestar esa tendencia, los estudiosos de la literatura debemos estar entrenados en un trabajo de archivo que nos permita ir más allá del circuito hegemónico de circulación de los textos literarios, debemos incorporar el ejercicio de conocer archivos físicos, revisar catálogos, bibliotecas, notas periodísticas, documentos de diversa índole en función de cuestionar constantemente el corpus instituido y las jerarquizaciones predeterminadas. En este sentido, resulta necesario también que nos familiaricemos con el manejo de datos más allá del contenido en sí mismo, por lo que se vuelve clave que aprendamos a manejarnos con estadísticas, cuadros, gráficos, tablas y figuras.

Para poder llevar a cabo esta tarea es necesario sumarle al ejercicio ya instalado de close reading, una lectura distante sobre el campo literario en función de poder descubrir las zonas 
invisibilizadas o aún desconocidas. La idea de "lectura distante" está trabajada por Franco Moretti y su literatura mundial, quien la define del siguiente modo:

el problema con la lectura cercana (...) es que requiere necesariamente un canon minúsculo (...) Y si queremos ver qué hay más allá del canon (...), la lectura cercana no servirá (...) ya sabemos leer textos, ahora tenemos que aprender a no leerlos. Lectura distante, donde la distancia, cabe repetir, es una condición del conocimiento; es lo que permite colocar el foco en unidades mucho más pequeñas o mucho más grandes que el texto $(2015$, p. 63).

Viene llevando a cabo un trabajo destacable en esta línea la investigadora brasileña Regina Dalcastagnè, quien ha realizado dos grandes estudios estadísticos a partir del montaje y organización de un extenso archivo, volcando resultados alarmantes. El primero de ellos llamado "A personagem do romance brasileiro contemporâneo" (2014) consistió en un relevamiento de datos a partir de un corpus de 258 novelas publicadas entre 1990 y 2004 por las tres editoriales más prestigiosas de Brasil (Companhia das Letras, Record y Rocco). En dicha investigación se recogieron estadísticas respecto del color de los personajes, del posicionamiento en las novelas, de sus principales ocupaciones y del estrato socioeconómico. En relación con los personajes, se identificó casi el $80 \%$ de personajes blancos, proporción que aumenta cuando se aíslan protagonistas y narradores (Dalcastagnè, 2014, p. 31). El impacto de esta ausencia aumenta al ver los porcentajes de las principales ocupaciones de los personajes. Mientras que los personajes blancos son básicamente amas de casa, artistas, escritores, estudiantes, etc., los personajes negros son bandidos, empleadas domésticas, esclavos, profesionales del sexo, etc. (Dalcastagnè, 2014, p. 41). La conclusión de la autora es contundente: la literatura es un espacio donde se validan representaciones del mundo social camufladas, muchas veces, bajo pretensiones de realismo o de atención a los recursos estéticos.

La segunda investigación llevada a cabo por Dalcastagnè titulada "A crítica literária em periódicos brasileiros contemporâneos" (2018), apunta al corpus de trabajo que investigamos los estudiosos de la literatura. En este caso, se buscó "identificar quais as correntes mais presentes, os autores de referência e as obras citadas em alguns dos periódicos mais representativos da área nos últimos 15 anos" (Dalcastagnè, 2018, p. 196). Para eso, "foram selecionadas, inicialmente, dez periódicos com certa tradição e bem classificados no ranking mais importante do mundo acadêmico brasileiro, o Qualis da Coordenação de Aperfeiçoamento de Pessoal de Nível Superior (Capes)" (Dalcastagnè, 2018, p. 196). Los resultados resultan un llamado de atención para nuestra área. Por un lado, porque el objeto de estudio de la mayor parte de las investigaciones se centra en las producciones de los escritores centrales del canon literario brasileño:

os nomes preferidos dos estudos literários brasileiros: Guimarães Rosa (com 121 textos), Machado de Assis (com 108), Carlos Drummond de Andrade (com 51), Antonio Candido (também com 51), Clarice Lispector (com 47) e Mário de Andrade (com 39) (Dalcastagnè, 2018, p. 204-205).

Por otro lado, porque cuando se investigan temas ligados a producciones marginalizadas no se consideran las obras, sino el fenómeno en tanto fenómeno colectivo:

Alguns autores parecem ser entendidos como "grandes demais" para dividir a análise com outros, enquanto nomes da literatura marginal, como Ferréz e Paulo Lins, além da própria Carolina Maria de Jesus, costumam ser discutidos em grupo, em textos panorâmicos (Dalcastagnè, 2018, p. 205).

Tomando en cuenta estos resultados podemos percibir lo que Moretti (2015) llama el "matadero" de la literatura, es decir, la alta selectividad y la eliminación de la mayoría de las obras de ficción en visiones posteriores y retrospectivas sobre y desde la historia de la literatura. Claramente lo que motoriza ese matadero en el caso aquí estudiado, lo que desplaza a algunos y coloniza el canon, es algo que Bourdieu sintetiza como habitus "por medio del cual los agentes participan de la historia objetivada de las instituciones" (2007, p. 93). Se trata de escritores que, sin formar propiamente un grupo, están muy próximos por su trayectoria social, lo que los hace pertenecer, incluso antes de querer ser escritores, al universo de los posibles. Este habitus, como 
quedó claro, responde a una representación letrada, que excluye del horizonte a los escritores o escritoras de trayectorias diversas.

Para conseguir llegar a los restos de ese matadero, es necesario un acercamiento archivístico y estadístico. Nuestra formación debe ampliar los horizontes metodológicos y debe apuntar a adquirir el conocimiento de las técnicas e instrumentos necesarios para poder cuestionar los márgenes conceptuales y valorativos respecto de lo que es la literatura y sus productores. En líneas generales, la crítica literaria carece de información en cuanto a las formas de acceder a un archivo o los programas informáticos para organizar la información y esta limitación no es inocente: la carencia de las herramientas de acceso a ciertas producciones fortalece cada vez más el corpus instituido.

Ante esta constatación, me parece importante recordar la relevancia de la crítica universitaria para repensar constantemente la teoría y la composición del canon, como señala Regina Dalcastagnè:

O peso da crítica universitária é visível na definição e redefinição do cânone passado, mas é ainda mais crucial no que diz respeito à produção literária contemporânea. Para obras que ainda não possuem um lastro de crítica e camadas de interpretações acumuladas, a atenção oferecida pelos acadêmicos representa um capital importante (2012, p. 196).

La crítica literaria, desde este punto de vista, debe considerar de manera activa la inclusión de obras desconocidas o silenciadas en función de intervenir en el canon. Entiendo intervención no en un sentido de práctica autoritaria y violenta, como puede remitir esta idea en el campo de lo político, ni de operación externa en un sentido más quirúrgico, sino la pienso como una práctica transformadora en el sentido en que la define Nelly Richard en su libro "En torno a los estudios culturales. Localidades, trayectorias y disputas" (2010):

Hablar de "intervención" es hablar de una participación activa en determinado campo de relaciones mediante un diseño táctico que busca modificar sus reglas (...) En rigor, tiene carácter de "intervención" cualquier corte transformador que se practique en las superficies de conocimientos normalizados (p. 80).

Intervenir el canon apunta así, desde el campo de la literatura, a ampliar la oferta de productos simbólicos y a aportar los conceptos y sensibilidades necesarias para poder otorgarles valor.

Ahora bien, esto no significa que los estudios de la literatura se desentiendan de los escritores hegemónicos. En un artículo titulado "La flexión del género en el texto cultural latinoamericano", de Sylvia Molloy (2002), escritora y ensayista argentina radicada en Nueva York, se plantea que, junto a la importancia de la recuperación histórica de textos olvidados, marginados, mezquinamente leídos, es necesario hacer un ejercicio de releer el canon establecido de otra manera o de diversas otras maneras. En otras palabras, es necesario hacer una lectura "fisurada" de las lecturas establecidas sobre el canon, dice Molloy: "Esa lectura o lecturas desviadas, permite reconocer esos nudos de resistencia que señalaba Foucault dentro del espacio circunscrito de la institución, pasajeras heterotopías que se desvían del proyecto disciplinador" (2002, p. 165). Molloy dice inspirarse en su hipótesis a partir de la lectura de un texto de Domingo Faustino Sarmiento, un autor argentino canónico del siglo XIX, titulado "Más-a-fuera". Se trata de una escena de los "Viajes" donde el narrador cuenta que se queda varado en una isla por cuatro días y se topa con cuatro náufragos norteamericanos que hacía cuatro años no hablaban con nadie más. Molloy relata que, en ese texto, Sarmiento se alarma ante la división de tareas domésticas entre los hombres y, sobre todo, por el perfil "afeminado" de uno de los náufragos. La lectura fisurada de Molloy sobre la escritura sarmientina tiene que ver con profundizar en esa escena otorgándole una lectura con perspectiva de género. La fórmula sería: volver a los clásicos para leerlos de un modo fisurado, de manera de romper con el a priori histórico que determina las posibilidades e imposibilidades de los enunciados, para decirlo en términos de Foucault (Molloy, 2002, p. 170).

De todos modos, muchas veces el trabajo de cuestionamiento en relación con la noción de "canon" resulta insuficiente desde las operaciones archivísticas de intervención o de fisura. En este punto es que propongo la tercera de las identidades que pienso necesarias para definir la tarea del estudioso de la literatura: la del etnógrafo. 
Muchas veces, son los propios conceptos incorporados los que limitan nuestra actividad y la amplitud de nuestra perspectiva crítica, partiendo de la idea preestablecida de lo que entendemos por "literatura" y por "escritor". Y no existe trabajo de archivo o de escritura que pueda ayudarnos a desarmarlos. El único modo de poder desprendernos de ciertas sensibilidades habituadas es acudir a la disciplina que toma como base de su ejercicio el desaprendizaje. Me refiero a la etnografía. Resulta necesario asumir que hay ciertas manifestaciones literarias que, para entenderlas como tal, tenemos que poner en cuestión nuestros valores y conceptos. De lo contrario, caemos en un modo endogámico de entender nuestro objeto de estudio. Tenemos que abrirnos al estudio de la literatura que "se procesa ahí, viva", como la define Marcelino Freire (Alves, 2010), es decir, entre diversas comunidades lectoras, muchas de ellas ajenas al circuito académico-hegemónico, como puede ser el estudio de la fanfiction, de la producción de la literatura de masas, de la literatura difundida por los booktubers, de la literatura que circula por los saraus de las periferias, de la literatura que se escribe en las cárceles, etc etc etc. Y, para ello, tenemos que ponernos el traje de etnógrafos y llevar a cabo un trabajo de campo que nos permita lograr una descripción densa que desafíe a la pretendida universalidad de los grandes paradigmas literarios.

Un ejemplo iluminador en este sentido es la investigación que el propio Víctor Vich volcó en su libro "El discurso de la calle. Los cómicos ambulantes y las tensiones de la modernidad en el Perú" (2001). Se trata de un análisis de las producciones de los cómicos ambulantes que realizaban performances en las plazas públicas de Lima durante los años 90. Para abordar dichos textos, Vich manifiesta explícitamente la urgencia de una actitud transdisciplinaria distinta frente a determinadas manifestaciones literarias: "Las performances orales se sitúan en un espacio que inevitablemente diluye las fronteras académicas y nos imponen con urgencia una actitud diferente" (2001, p. 17). Así, junto al análisis textual y la teoría crítica, asume como opción metodológica fundamental para dicha investigación un trabajo de campo basado en la etnografía. Es a partir de esa decisión que puede correrse de una concepción de literatura bastante limitada centrada en la letra escrita y en un circuito asociado a la edición. Dice Vich:

el tiempo que pasé en las calles de Lima me hizo reformular una serie de ideas y prejuicios que tenía frente a la investigación académica, frente a mi propia formación literaria y, sobre todo, frente a las discutibles fronteras disciplinarias. Partiendo de la literatura me estoy refiriendo tanto a los impulsos por demostrar el carácter histórico y variable de la construcción del canon literario como también a las opciones interdisciplinarias respecto de una hermenéutica más consciente de la densidad cultural de los textos (2001, p. 24).

La investigación de Vich (2001) parte de un corrimiento del lugar de confort en relación con el objeto de estudio y en relación con la imaginación de un lugar "neutral" desde donde producir el conocimiento. Ese movimiento no solamente es simbólico, sino que es físico: el crítico literario realizó reiterados trabajos de campo etnográfico por las plazas de Lima durante cuatro años de investigación.

Como afirma la antropóloga argentina Rosana Guber en su libro "La etnografía. Método, campo y reflexividad" (2011): "Si acaso por un tiempo vale la pena meter los pies en el barro y dejar la comodidad de la oficina y las elucubraciones del ensayo es porque tanto los pueblos sometidos a la globalización como sus apóstoles operan en marcos de significación etnocéntricos" (p. 22). En tanto críticos literarios, en cierto momento de nuestras investigaciones debemos ir más allá de los libros para encontrarnos con los lectores, productores y demás actores que participan de los diversos circuitos y escenas literarias. Ahora bien, este ejercicio no se hace fácilmente, es necesario para ello que, una vez más, nos formemos con las herramientas metodológicas necesarias para llevar a cabo un trabajo de campo no dirigido y eficiente. La mayoría de los críticos desconocemos las técnicas y los instrumentos para llevar a cabo una observación participante, una entrevista no dirigida y para asumir la reflexividad que las atraviesa e, insisto, ese desconocimiento responde a una falta de formación en nuestra tarea crítica que limita enormemente el campo de acción y el horizonte de cambio. La metodología es una herramienta que determina nuestro objeto de estudio y es fundamental que ampliemos nuestros conocimientos al respecto para salir de nuestra perspectiva grafocéntrica, letradocéntrica y blancocéntrica. 
Finalmente, más allá de las intervenciones que las investigaciones de los estudiosos de la literatura podemos llevar a cabo en el ámbito del ejercicio de nuestra profesión en relación con la teoría y la metodología, creo importante que la crítica literaria asuma la necesidad de llevar a cabo su tarea más allá de los espacios institucionales. Es en este sentido que postulo que la cuarta identidad del crítico debe ser la del difusor. El crítico literario debe asumir, en cierto momento de su investigación, una identidad anfibia y debe animarse a circular por mundos que no son su habitat natural. ¿Qué mundos? Cabe, aquí, asumir la primera persona para desarrollar este punto con un ejemplo. Durante muchos años de mi carrera me dediqué a investigar las producciones de las periferias de diversas ciudades de Brasil. El ineditismo de la elección de mi objeto de estudio y de la metodología interdisciplinaria que implementé me llevaron a asumir un papel inesperado frente a estas literaturas en América Latina: de repente me encontré con la necesidad de facilitar el acceso a esas producciones en los países hispanohablantes y de montar una estructura crítica para su recepción. Ante esta realidad, tuve que empezar a gestionar la posibilidad de traducir ciertos autores y me convertí, así, en una especie de agente literaria implicada en la oferta y promoción de un tipo de consumo novedoso y en hacer el puente entre el autor y el editor. Asimismo, siendo que los textos ofrecidos se caracterizaban por un dialecto restringido a las periferias, tuve que asumir el papel de traductora y, otras veces, de prologuista y antologista. Luego, tuve que ocuparme de la difusión de prensa de esos libros y de la organización y curaduría de eventos para contribuir a su divulgación. Sin dejar de lado en ningún momento mi naturaleza de crítica literaria, terminé circulando por los mundos de la industria del libro, como la gestión editorial, la traducción y la prensa.

Resulta fundamental asumir que el rol del crítico debe apuntar, también a la "construcción" y "organización" de la producción literaria. Somos articuladores de narrativas y debemos asumir asimismo nuestro perfil de gestores o curadores de nuestro objeto de estudio. Como dice Víctor Vich, "un buen gestor es capaz de presentar objetos culturales de manera diferente a como lo hace el Estado o el mercado" (2018, p. 52).

En suma, la salida para el estado de inercia de los estudios de literatura, desde mi punto de vista, debe tomar en cuenta estas cuatro identidades, entendidas como herramientas y habilidades que deben formar parte de la formación y del ejercicio profesional de un estudioso de la literatura, sin distinciones. Todas ellas son simultáneas y se retroalimentan mutuamente.

La crítica literaria del modo en la que la estoy entendiendo, más que una disciplina, es una práctica que permite activar sensibilidades sobre lo establecido, por lo que crea otras formas de imaginarlo. Una buena metáfora para graficarla, quizás, es la idea del "site specific", categoría perteneciente al universo del arte que se refiere a aquellas creaciones artísticas que establecen un diálogo creativo con un determinado lugar de paso cotidiano, empalmando un nuevo sentido a ese espacio que de otra forma pasaría desapercibido. Hay una artista norteamericana, Rachel Benedum, que tiene una obra emplazada en una colina pequeña con los costados ahuecados, donde ella colocó un broche gigante de madera como si ese hundimiento fuera producto de la presión del broche. Hacer crítica situada sería algo así como ese diálogo entre el broche y la colina.

Felizmente, como quedó claro en los ejemplos, desde hace rato se vienen trazando una serie de búsquedas para salir de la inercia en la que se encuentran los estudios de la literatura y que se proponen como un modo de hacer, una estrategia de intervención teórico-metodológicadiscursiva que pretende activar críticamente nuevas coordenadas de representación en lugar de quedarse en la administración de lo establecido. Una producción crítica desde y sobre la literatura que, a partir de un cruce de lenguajes y metodologías, interviene en la mirada sobre lo cotidiano, corriendo este concepto de la idea de inercia del día a día y llevándolo, tal y como lo define Víctor Vich (2018, p.48), al campo de la creatividad y de la agencia. Hoy en día, más que nunca, es necesario formarse como estudioso de la literatura en diálogo con la hora histórica, pensando nuestras prácticas como intervenciones. No basta con analizar los textos de la literatura en su dimensión intradiscursiva, es necesario comprometer nuestro trabajo y su destinatario en un trabajo de desmontaje y rearticulación de sentidos en función de poner en cuestión los discursos del consenso y disputar su lugar incuestionable. 


\section{Referências}

ALCOFF, Laura (2016). Uma epistemologia para a próxima revolução. Revista Sociedade e Estado. Brasília, v. 31, n. 1, p. 129-143. Disponible en: https:/ / bit.ly/3a98n6T Accedido el: 30 ago. 2021.

ALVES, David (2010). Curta Saraus. São Paulo: Coletivo Arte na Periferia. Disponible en: https://www.youtube.com/watch?v=cMDBPhZmFe4 Accedido el: 30 ago. 2021.

BARTHES, Roland (2003). ¿Qué es la crítica?. In: Ensayos críticos. Traducción de Carlos Pujol. Buenos Aires: Seix Barral.

BOURDIEU, Pierre (2007). El sentido práctico. Buenos Aires: Siglo XXI Editores.

COMPAGNON, Antonie (2015). El demonio de la teoría. Literatura y sentido común. Traducción de Manuel Arranz. Acantilado: Barcelona.

DALCASTAGNÈ, Regina (2012). Literatura brasileira contemporânea: um território contestado. Vinhedo: Horizonte.

DALCASTAGNÈ, Regina (2014). A personagem do romance brasileiro contemporâneo. Estudos de Literatura Brasileira Contemporânea, Brasília, n. 26, p. 13-71. Disponible en: https:/ / bit.ly/2WJS1P0 Accedido el: 30 ago. 2021.

DALCASTAGNÈ, Regina (2018). A crítica literária em periódicos brasileiros contemporâneos. Estudos de Literatura Brasileira Contemporânea, n. 54, p. 195-209. Disponible en: https:// bit.ly/3AqGdiF Accedido el 30 de ago. 2021.

FOUCAULT, Michel (2002). El a priori histórico y el archivo. In: FOUCAULT, Michel. La arqueología del saber. Buenos Aires: Siglo XXI Editores.

GUBER, Rosana (2011). La etnografia: método, campo y reflexividad. Buenos Aires: Siglo XXI Editores.

LUDMER, Josefina (2010). Aquí América Latina. Una especulación. Buenos Aires: Eterna Cadencia.

MOLLOY, Sylvia (2002). La flexión del género en el texto cultural latinoamericano. Cuadernos de Literatura, Bogotá, n. 8, p. 161-167. Disponible en: https:// bit.ly/3iBbVDB Accedido el: 30 ago. 2021.

MORETTI, Franco (2015). Lectura Distante. Traducción de Lilia Mosconi. Buenos Aires: Fondo de Cultura Económica.

RICHARD, Nelly (2009). La cita académica y sus otros. In: RICHARD, Nelly. Campos cruzados. Crítica cultural, latinoamericanismo y saberes al borde. La Habana: Fondo Editorial Casa de las Américas.

RICHARD, Nelly (2010). En torno a los estudios culturales. Localidades, trayectorias y disputas. Santiago de Chile: Arcis/Clacso.

SVAMPA, Maristella (2008). Notas provisorias sobre la sociología, el saber académico y el compromiso intelectual. In: HERNANDEZ, Valeria; SVAMPA, Maristella (orgs.). Gèrard Althabe. Entre dos mundos. Reflexividad y compromiso. Buenos Aires: Prometeo.

VICH, Víctor (2001). El discurso de la calle. Los cómicos ambulantes y las tensiones de la modernidad en el Perú. Lima: Fondo editorial Pontificia Universidad Católica del Perú.

VICH, Víctor (2018). ¿Qué es un gestor cultural? En defensa y en contra de la cultura. In: YÁÑEZ CANAL, Carlos (org.) (2018). Práxis de la gestión cultural. Bogotá: Editorial Universidad Nacional de Colombia 